\title{
Oral administration of Cimicifuga racemosa extract attenuates psychological and physiological stress responses
}

\author{
Isao Nadaoka ${ }^{1}$, Masaaki Yasue ${ }^{1}$, Manabu SAmi ${ }^{1}$, Yasushi Kitagana ${ }^{1}$, and Yoshihiko Koga ${ }^{2}$ \\ ${ }^{1}$ Research Laboratories for Fundamental Technology of Food, Asahi Group Holdings, Ltd., Moriya 302-0106, Japan and ${ }^{2}$ Department \\ of Neuropsychiatry, Kyorin University School of Medicine, Mitaka 186-8611, Japan
}

(Received 13 February 2012; and accepted 3 March 2012)

\begin{abstract}
Dried rhizomes of Cimicifuga racemosa (CR), which are known as black cohosh, have been widely used as herbal dietary supplements to treat menopausal symptoms. The present study examined the effect of CR extracts on human psychological and physiological responses to acute stress induced by mental arithmetic tests, by measuring the subjective stress intensity, the brain-wave patterns according to electroencephalography, and the concentrations of salivary chromogranin-A and cortisol. The experiments were performed double-blind and their order was counterbalanced. Treatment with CR significantly attenuated the elevated subjective perception of stress and the increased salivary chromogranin-A levels compared with placebo treatment. CR extract also rapidly recovered the decrease in alpha waveband induced by performing the mental arithmetic task. We therefore propose that $\mathrm{CR}$ extracts might be suitable for the prevention and treatment of stressrelated disorders.
\end{abstract}

Cimicifuga racemosa (CR) of the Ranunculaceae family is indigenous to eastern North America, and its range extends as far as south Florida. Dried rhizomes of CR are known as black cohosh and have been widely used as herbal dietary supplements for almost five decades. Historically, Native American women ingested water extract of CR for pain relief during menstruation and childbirth. In recent years, ethanolic and isopropanolic extracts of $\mathrm{CR}$ have been used for the treatment of general menopause symptoms including hot flushes, profuse sweating, irritability, and anxiety; in addition, its popularity has grown among women hoping to avoid the potential toxicity of classical hormone-replacement therapy (4).

With respect to the commercial CR product Remi-

Address correspondence to: Isao Nadaoka, Department of Infant Milk and Analytical Technology, Research and Development Center, Wakodo Co., Ltd., 2-2, Wakabacho, Chofu-shi, Tokyo, 182-0003, Japan

Tel: +81-3-3300-9601, Fax: +81-3-3300-0122

E-mail: nadaokai@wakodo.co.jp femin $^{\circledR}$, which contains $1 \mathrm{mg}$ triterpene glycosides per 20-mg tablet, some pharmacological studies have been undergone and these results show that, rather than exhibiting estrogen-like activities, its underlying mechanisms are dopaminergic (5) and serotonergic $(6,39)$. However, the details of its actions remain unclear. Investigations into the chemical constituents of CR revealed alkaloids (19), isoflavones (52), phenylpropanoids (8), and more than 20 highly oxygenated triterpene glycosides with cycloartane skeletons, which are secondary metabolites believed to have biological effects $(28,56)$. We recently observed anti-stress activities of CR extract in mice (31): a single oral administration of CR extract (200-1,000 mg/kg) significantly attenuated plasma corticosterone and aspartate aminotransferase (AST) levels that had been increased as a result of enforced immobilization. Bioassay-guided fractionation of CR extracts isolated 10 triterpenes, among which actein, 23-epi-26-deoxyactein, and cimiracemoside F (100 mg/kg, per os) were shown to contribute to the anti-stress effects. Moreover, oral administration of CR extract affects immobilization 
stress-induced changes in murine cerebral monoamine metabolism (32). Although many clinical studies reported the efficacy of CR extracts for relieving menopausal symptoms, no investigations have been carried out into their anti-stress properties in humans.

Lifetime exposure to stress can have important consequences for health. Stress has been related to a large number of pathologies, such as cardiovascular disease, atherosclerosis, cancer, gastric ulcer, and type 2 diabetes $(11,51)$. Two main body systems are involved in the stress response: the sympathetic adrenomedullary (SAM) system and the hypothalamus-pituitary-adrenal axis (HPA-axis). Recently, there has been increasing interest in measuring salivary chromogranin- $\mathrm{A}(\mathrm{CgA})$ concentrations as an indicator of psychological stress levels $(22,33,34$, 36-38). Human $\mathrm{CgA}$ is produced by the submandibular glands, and secreted into the saliva (48); it can thus be measured non-invasively with relatively little stress (26). It belongs to a family of highly acidic proteins, which are co-stored and co-released with catecholamine in the adrenal medulla $(3,57) . \mathrm{CgA}$ was shown to be a valuable indicator of sympathoadrenal activity (55), and is a possible alternative to the measurement of plasma catecholamine concentrations (23). Moreover, salivary $\mathrm{CgA}$ secretion might be an index for activated sympatho-adrenal activity in the stress response $(33,59)$. Although salivary cortisol reflects the extent of the HPA-axis activity in response to physiological and psychological stress conditions (45), salivary CgA changes more rapidly and more sensitively in response to psychological stressors than salivary cortisol (33).

Electroencephalograms (EEGs) are used to measure brain waves. Each brain-wave pattern is associated with a different mood state and state of consciousness. Four basic brain wavebands make up an EEG: delta, theta, alpha, and beta. The alpha waveband is observed during wakefulness when there is relaxed and effortless alertness. Therefore, a high alpha waveband has been used as an index of arousal, relaxation, and anti-stress $(1,2,30,40)$.

A variety of tasks have been used as acute stressors in psychological and physiological stress studies. The Uchida-Kraepelin (U-K) test involves a questionnaire modified from Kraepelin's arithmetic test (27). It is a serial addition test, requiring subjects to perform calculations as rapidly and accurately as possible within $60 \mathrm{~min}$. It requires focused effort and attention by the subject, making it useful for the assessment not only of character but also of psychological stress $(20,29)$. Indeed, it has been widely used as a psychological stressor to assess work apti- tude $(49,53,58)$.

The present study measured subjective stress intensity, brain-wave patterns, and concentrations of salivary $\mathrm{CgA}$ and cortisol as indices of acute stress responses to the U-K test. We also examined the buffering effects of CR extract on such responses by asking participants to consume a capsule containing $200 \mathrm{mg}$ CR extract before exposure to the acute stressor. As the effects of drug treatment can be dependent on participant expectations, the placebo condition involved the consumption of a capsule containing lactose. All participants engaged in the two conditions in a double-blind counterbalanced order.

\section{MATERIALS AND METHODS}

Participants. Twenty healthy adult males (age range: 20-29 years) participated in experiment 1. Eleven healthy adults (six males and five females; age range: 20-22 years) participated in experiment 2 (see below). The participants had no history of psychological or psychiatric disease, no current mental or physical symptoms including depression, and no recent history of drug use. Before the experiments, the participants were asked to maintain their general habits, to sleep as long as usual, to refrain from heavy physical activity on the day before the experiments, to drink only water, and not to smoke or take any stimulants such as alcohol, coffee, cola, caffeine, or tea from the night before the experiments. The experiments were scheduled to be performed in the morning, and all participants signed an informed consent form after receiving verbal and written information about the study. The experiments were conducted in accordance with the Declaration of Helsinki, and the protocol and conduct were approved by the Ethics Research Committee of Asahi Group Holdings, Ltd (Tokyo, Japan).

Supplementation design. The participants were randomly assigned to one of two groups, based on a crossover experimental design, receiving either CR extract (Nippon Funmatsu Yakuhin, Osaka, Japan) or placebo (lactose). The CR extract $(200 \mathrm{mg}$ ) and placebo capsules were indistinguishable, and were taken with $100 \mathrm{~mL}$ water. Two sessions were conducted with a 7-day interval. The study design was double-blind, with neither the participants nor the experimenters knowing which group the subjects were in until the last one had completed the study.

Psychological stress protocol; Experiment 1. The 
experimental schedules are shown in Fig. 1. The participants were instructed to eat a light breakfast on the morning of the experiment, and caffeine-containing beverages were not allowed. On arrival, the participants signed a consent form, and underwent psychological measurements and saliva collection. After a 30-min rest period, they were administered one of the two identical capsules in a pre-determined randomized order. After a $60-\mathrm{min}$ rest period, the U-K test was performed in a 30-min work/5-min rest cycle. The test used pre-printed paper containing 34 lines of random, single-digit, horizontally aligned numbers. For each minute of the test, the subjects were instructed to begin a new line regardless of their position on the current line. Each line contained so many calculations that the subjects were unable to complete them before being prompted to move on by the examiner. Saliva samples and psychological measurements were obtained during and after the U-K test. Participants returned for a second test at the same time 1 week later, when the same procedure was followed with administration of the alternative capsule.

Psychological stress protocol; Experiment 2. Participants were instructed as described for experiment 1. They were fitted with physiological measurement equipment, seated in an air-conditioned booth for approximately $30 \mathrm{~min}$ after arrival at the laboratory, and administered one of the two identical capsules in a pre-determined randomized order. Both the subjects and the experimenters were blind to the con-

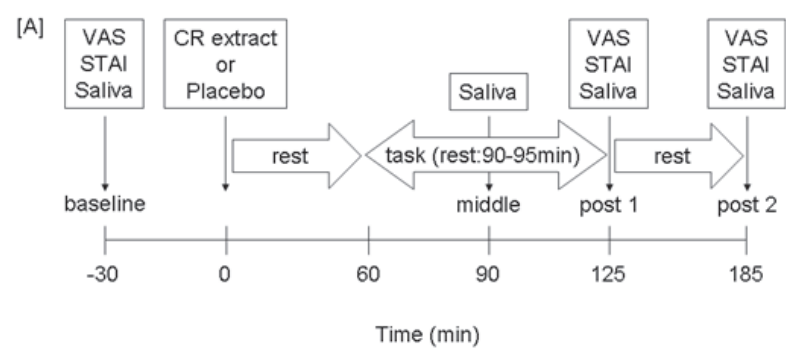

[B]

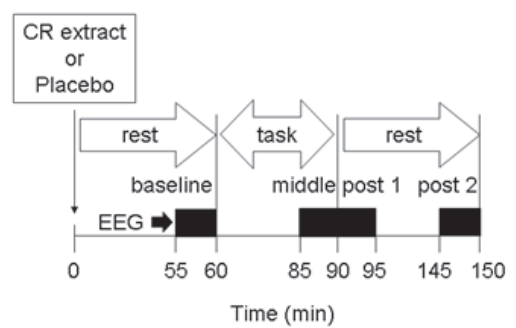

Fig. 1 Protocols for experiment $1(\mathrm{~A})$ and experiment 2 (B). tents of the capsule. The modified (m) U-K test was then performed, with the answers being given orally. Brain-wave data were collected before the mU-K test, and 0 and $60 \mathrm{~min}$ after the mU-K test during a 5 -min period in which the eyes of the participants were closed. The participants returned for a second test at the same time 1 week later, when the same procedure was followed with administration of the alternative capsule.

Psychological measures. A psychological evaluation of the stressfulness was performed using a visual analog scale (VAS) ranging from $0-10$ with 0 indicating no stress. In addition, the participants completed the Japanese version (35) of the state section of the State-Trait Anxiety Inventory (STAI) (50), which measures state anxiety.

Salivary analysis. Saliva was collected using Salivettes ${ }^{\circledR}$ (Sarstedt, Numbrecht, Germany). Participants were instructed to introduce a cotton swab into their mouths for exactly $1 \mathrm{~min}$, without chewing it, and to move the swab around in a circular pattern to collect saliva from all of the salivary glands (43). The swab was then removed, and the saliva was extracted by centrifugation at $1,500 \times g$ for $10 \mathrm{~min}$. The samples were frozen at $-20^{\circ} \mathrm{C}$ until required for analysis. The salivary $\mathrm{CgA}$ concentration was determined by an enzyme-linked immunosorbent assay (ELISA) using the YK070 Human CgA EIA kit (Yanaihara Institute Inc., Shizuoka, Japan). The salivary cortisol levels were assayed using the High Sensitivity Salivary Cortisol EIA kit (Salimetrics LLC, State College, PA). The inter- and intra-assay variation was below $10 \%$.

EEGs. In order to assess the relaxation effects, we analyzed the alpha waves in the EEG background activity, which are observed within the $8-$ to- $13-\mathrm{Hz}$ frequency range. Alpha waves are observed predominantly in the occipital area of the scalp when the eyes are closed. We utilized the international 10-20 system of electrode placement, and located electrodes at 19 sites (Fp1, Fp2, Fz, F3, F4, F7, F8, Cz, C3, C4, T3, T4, T5, T6, Pz, P3, P4, O1, and O2) on the scalp. The linked ear lobes served as a reference. We calculated the power spectrum (RMS) for the alpha-wave frequency range at $0.5-\mathrm{Hz}$ intervals using the Fast Fourier Transform (FFT), and made a topographic map for each frequency range.

Statistical analysis. Psychological data were analyzed using repeated-measures analyses of variance 
(ANOVAs) with two within-participant factors: the condition (placebo and CR extract) and the period (baseline, post 1, and post 2). Other data were analyzed using repeated-measures ANOVAs with two within-participant factors, the condition (placebo and $\mathrm{CR}$ extract) and the period (baseline, middle, post 1 , and post 2). Post-hoc analyses using least significant difference (LSD) tests were conducted to examine which combinations of data points differed significantly. Significance was assumed at $P$-values $<0.05$. Pearson correlation coefficients were computed among the change scores (scores at the post 1 - scores at the baseline) of each parameter to examine the relationship between the psychological and physiological parameters. All results represent means \pm standard error of the mean (SEM). PASW Statistics 18 software (SPSS Inc. 2009) was used to perform all analyses.

\section{RESULTS}

\section{Experiment 1; Psychological measures}

The psychological data are shown in Tables 1 and 2 . The subjective stress feeling was significantly increased by task performance in both groups, and that the post 1 value of the CR-extract group was significantly lower than that of the placebo group. The significant increases in state anxiety score caused by the task recovered after the 60 -min rest period in both groups, with no significant difference in values.

\section{Experiment 1; Salivary cortisol and CgA levels}

Fig. 2A and B shows the temporal variation of salivary cortisol and salivary CgA levels. We observed significant increases in salivary cortisol levels caused by the task followed by recovery after a 60 -min rest period in both groups, with no significant difference

Table 1 Temporal changes in subjective stress feeling scores

\begin{tabular}{llll}
\hline & Baseline & \multicolumn{1}{c}{ Post 1 } & Post 2 \\
\hline Placebo & $2.3 \pm 0.4$ & $4.4 \pm 0.5$ & $2.7 \pm 0.4$ \\
CR extract & $2.2 \pm 0.5$ & $3.1 \pm 0.4 * *$ & $2.9 \pm 0.5$ \\
\hline
\end{tabular}

Data represent the mean \pm SEM of values in each group $(n=20)$. $P$-value for two-way ANOVA followed by LSD test $(* * P<0.01$ vs. Placebo).

Table 2 Temporal changes in state anxiety scores

\begin{tabular}{lccc}
\hline & Baseline & Post 1 & Post 2 \\
\hline Placebo & $39.3 \pm 1.9$ & $46.7 \pm 2.1$ & $37.4 \pm 1.9$ \\
CR extract & $39.1 \pm 1.6$ & $45.5 \pm 2.0$ & $39.3 \pm 1.7$ \\
\hline
\end{tabular}

Data represent the mean \pm SEM of values in each group $(n=20)$. in values. On the other hand, the treatment with $\mathrm{CR}$ extract significantly attenuated the elevated salivary $\mathrm{CgA}$ at the middle, post 1 , and post 2 points in comparison with the placebo group.

\section{Experiment 2; EEGs}

The topographical changes in the alpha waveband $(8.0-13.0 \mathrm{~Hz})$ are shown in Fig. 3. As the temporal variations in the amounts of alpha wavebands (9.0 $9.5 \mathrm{~Hz})$ from the left $\left(\mathrm{O}_{1}\right)$ or right $\left(\mathrm{O}_{2}\right)$ occipital area were most strongly affected by the task, we analyzed these data (Fig. 4). The amounts of alpha wavebands $(9.0-9.5 \mathrm{~Hz})$ in both occipital areas were decreased during the task in both groups, and that only the CR-extract group showed tendency of recoveries from post 1 to post 2 without significant.
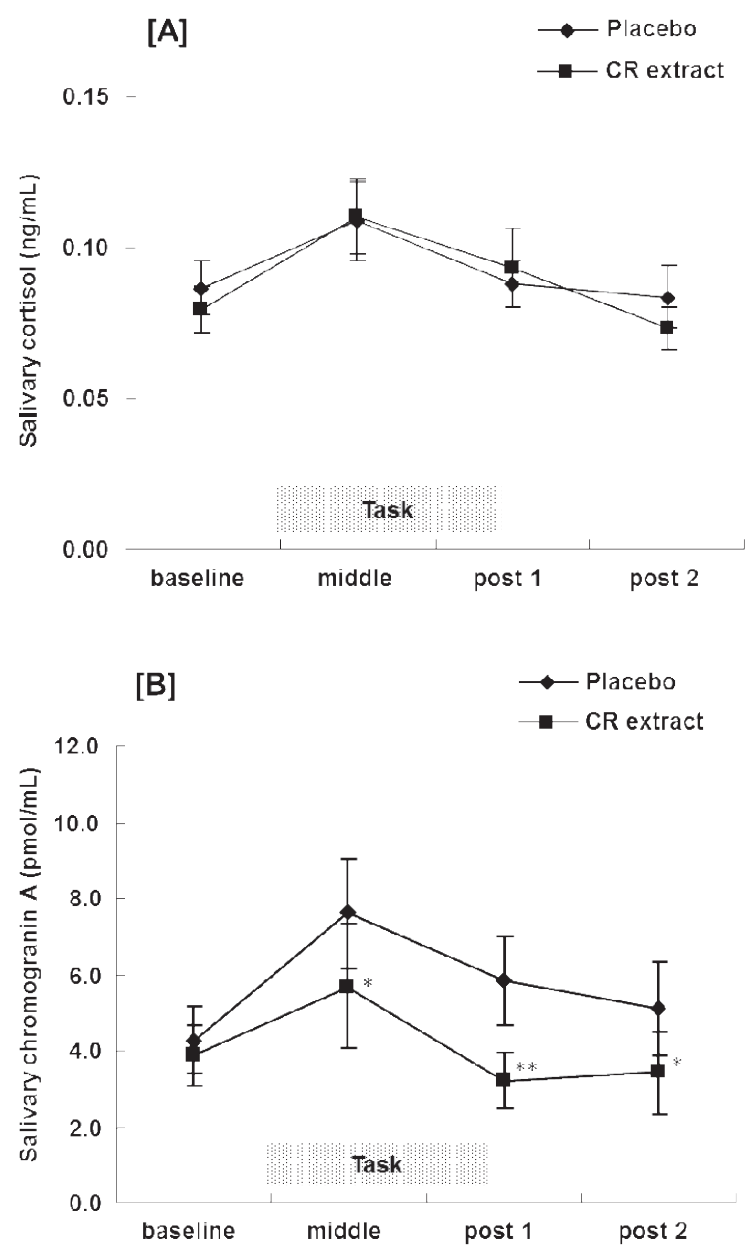

Fig. 2 Temporal variations of salivary cortisol concentrations (A) and salivary chromogranin A concentrations (B) at each time point. Data represent the mean \pm SEM of values in each group $(n=20)$. $P$-value for two-way ANOVA followed by LSD test $\left({ }^{*} P<0.05,{ }^{* *} P<0.01\right.$ vs. Placebo). 
Correlation between psychological and physiological parameters

We tried to calculate the correlation coefficients for each parameter, in order to understand any patterns in the changes. We also determined the correlations between the subjective stress feeling score, STAI state score, and salivary $\mathrm{CgA}$, because the salivary cortisol levels did not increase significantly from baseline to post 1 after performing the task. These results revealed a positive and significant correlation between the subjective stress feeling score and STAI state anxiety $(r=0.82, P<0.01)$, and a positive and tendency of correlation between the subjective stress feeling and salivary $\mathrm{CgA}(r=0.40, P=0.08)$, and between the STAI state score and salivary $\mathrm{CgA}(r=$ $0.43, P=0.06)$.

\section{DISCUSSION}

Our main findings suggested that the acute stress responses elicited by the U-K test were reduced by the oral administration of $200 \mathrm{mg}$ CR extract. The experimental procedure was indeed able to induce stress, as exposure to the U-K test increased the subjective perception of stress, and the salivary cortisol and CgA levels, but decreased the alpha wave-

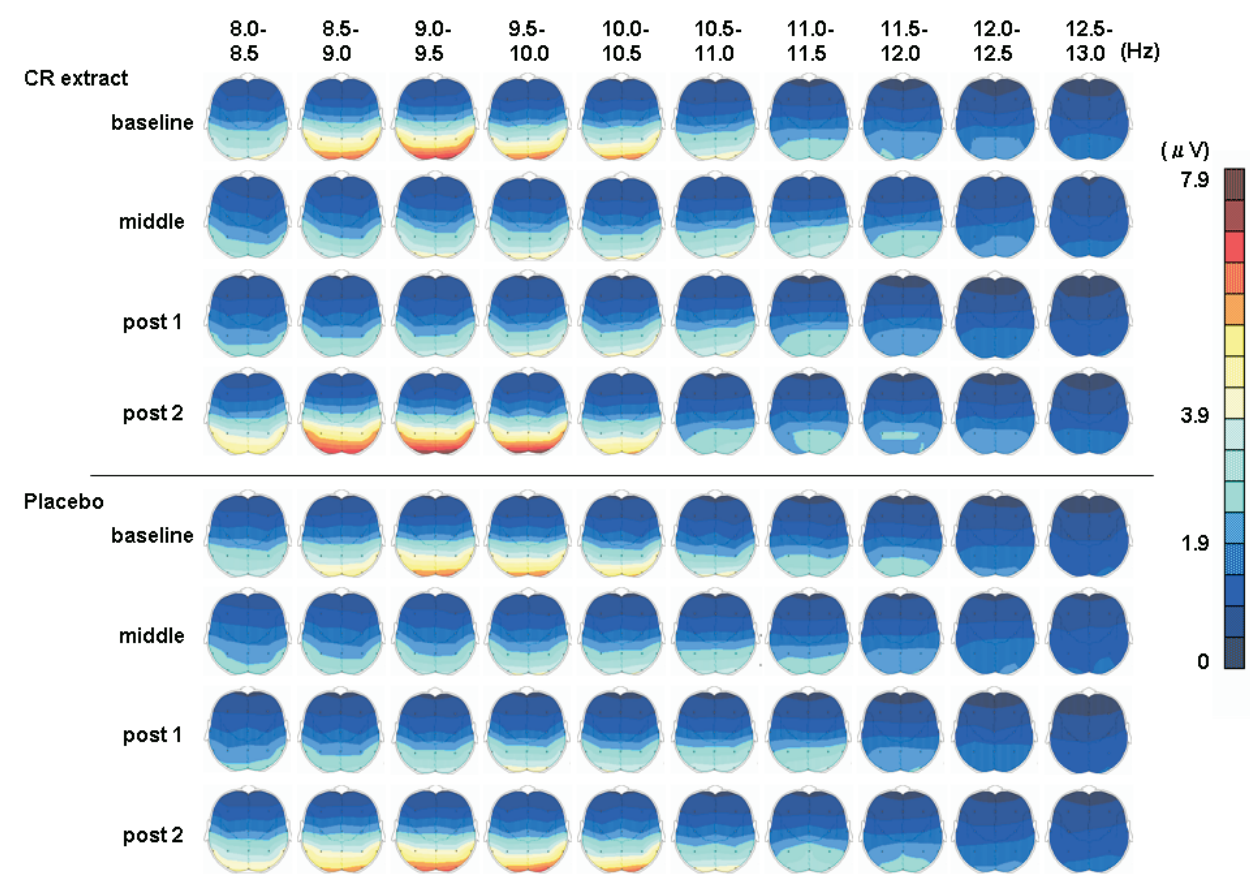

Fig. 3 Topographical changes in alpha wavebands at each time point.

$\left[0_{1}\right]$

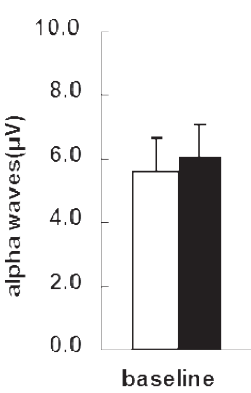

口Placebo

- CR extract

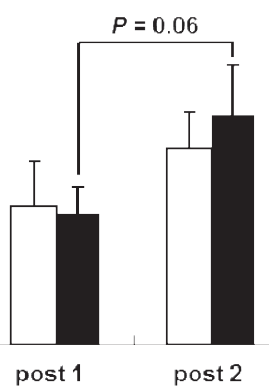

$\left[\mathrm{O}_{2}\right]$

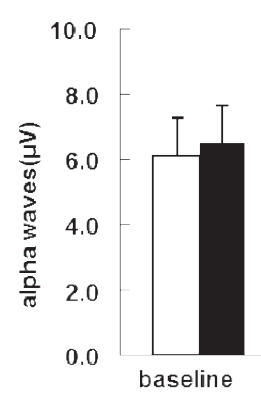

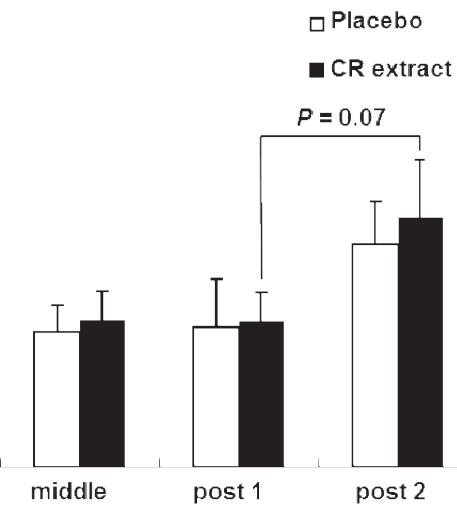

Fig. 4 Mean amount of 9.0-9.5 Hz waveband from left $\left(\mathrm{O}_{1}\right)$ and right $\left(\mathrm{O}_{2}\right)$ occipital areas at each time point $( \pm \mathrm{SEM})$. $P$-value for two-way ANOVA followed by LSD test. 
band. Experiment 1 was shown to be a reasonable procedure for evaluating the effect of $\mathrm{CR}$ extracts on psychological and physiological stress responses; however, correlations could not be calculated for experiment 2 as only one parameter was measured. The beneficial effects of CR extract were consistently observed not only in psychological stress responses, such as the subjective perception of stress, but also in physiological stress responses, such as the salivary $\mathrm{CgA}$ and the alpha waveband. Moreover, there was no difference in the total number of sums calculated in the U-K test between the placebo and $\mathrm{CR}$-extract groups, indicating that the $\mathrm{CR}$ extract did not reduce the calculation capability. Although it is possible that the buffering effect was induced by a placebo effect, as is frequently seen in medical clinical trials, we employed a double-blind crossover study design to prevent this.

In experiment 1 , although salivary cortisol levels were significantly increased by the task, the rise was minimal. This could be explained by an effect of circadian rhythm, as the experiment was always conducted in the morning (43). Therefore, although we previously showed that CR extract significantly attenuated the immobilization stress-induced increase in plasma corticosterone in mice (31), a similar effect was not observed on salivary cortisol in humans. However, treatment with CR extract significantly attenuated the elevation of salivary $\mathrm{CgA}$ and subjective stress feelings, and rapidly recovered the decrease in alpha wavebands compared with the placebo group. These results suggest that CR extract affects the SAM system during the performance of stressful tasks. Our studies on mice (31) and this study on humans suggested that $\mathrm{CR}$ extract interacted with both the HPA axis and the SAM system during stress. As Chrousos and Gold (10) discussed, the HPA axis and the SAM system could interact at many central sites to coordinate the stress response. The neurons that release corticotrophin-releasing factor (CRF) project from the lateral paraventricular nuclei (PVN) in the hypothalamus to sympathetic hindbrain regions (47), and, conversely, catecholaminergic fibers from the locus coeruleus (LC)-noradrenergic system project to the PVN $(14,15,46)$. Furthermore, the administration of CRF to LC neurons increases the firing rate $(17,21)$, and norepinephrine (NE) is a potent stimulus for the release of CRF $(7,15)$. CRF controls the secretion of adrenocorticotropic hormone (ACTH) from the anterior pituitary, which stimulates the adrenal cortex secretion of glucocorticoid hormones, mainly corticosterone in mice and cortisol in humans (60). Many studies have observed that immobilization stress activates the HPA axis, and increases the release of monoamines in the brain such as NE, serotonin (5-HT), and dopamine (DA) $(9,25,44,54)$. Moreover, serotonergic projections from the dorsal raphe nucleus inhibit firing of the LC, whereas noradrenergic projections from the LC have an excitatory effect on cell bodies in the dorsal raphe (24). Agonists of the $5-\mathrm{HT}_{1 \mathrm{~A}}$ receptor and selective 5-HT-reuptake inhibitors (SSRIs) are clinically useful for the treatment of various anxiety disorders $(13,16)$. Thus, the relationships among NE, 5-HT, and DA play important roles in the regulation of the SAM system during stress.

Several previous studies have reported that CR extract interacts with neurotransmitters such as 5-HT $(6,32,39)$ and DA (5). In vitro, CR extract acts as agonist of various 5-HT receptors, particularly $5-\mathrm{HT}_{1 \mathrm{~A}}, 5-\mathrm{HT}_{1 \mathrm{D}}$, and $5-\mathrm{HT}_{7}$. CR extract also shows receptor-mediated functional activity, as demonstrated by cyclic AMP (cAMP) induction in human embryonic kidney cells stably overexpressing the $5-\mathrm{HT}_{7}$ receptor (6). We believe that the oral administration of CR extract prior to stress exposure might act as a $5-\mathrm{HT}_{1 \mathrm{~A}}$ agonist and attenuate SAM or HPA-axis activity. CR extract reportedly acts as a competitive ligand and a partial agonist for opiate receptors (41, 42), similar to 5-HT receptors. Additionally, CR extract and isolated cycloartane glycosides have gamma-aminobutyric acid $(\mathrm{GABA})_{\mathrm{A}}$ receptor-modulating effects (12), which could also be relevant to the present results. Thus far, little is known about the pharmacokinetics and metabolites of CR extract. A recent study, however, provided the first evidence for the bioavailability of actein after oral administration to rats (18). It remains to be clarified whether these compounds penetrate the blood-brain barrier for efficient DA, 5-HT, opioid, and $\mathrm{GABA}_{\mathrm{A}}$ receptor modulation in vivo; this should be addressed in future studies.

The present results could be interpreted as indicating that a change in the central nervous system elicited the reduction of acute stress responses. They also suggest that such reduction of physiological stress responses can be subjectively monitored, at least in part, and might reduce subjective stress feelings. Consequently, it appears that CR extract plays both a physiological and a psychological anti-stress role via modulation of central nervous system activity. However, we neither directly evaluated parameters reflecting such functions, nor assessed the effects of the CR extract on HPA-axis stress-induced activation. Further studies are needed to investigate 
such neural and endocrine mechanisms. Nevertheless, we propose that CR extracts might be suitable for the prevention and treatment of stress-related disorders.

\section{Acknowledgements}

We greatly appreciate the help of the participants in this study. We would like to thank C. Konagai, A. Sawada, and T. Mitani for their excellent technical assistance.

\section{REFERENCES}

1. Abdou AM, Higashiguchi S, Horie K, Kim M, Hatta H and Yokogoshi H (2006) Relaxation and immunity enhancement effects of gamma-aminobutyric acid (GABA) administration in humans. Biofactors 26, 201-208.

2. Barry RJ, Clarke AR, Johnstone SJ and Rushby JA (2008) Timing of caffeine's impact on autonomic and central nervous system measures: Clarification of arousal effects. Biol Psychol 77, 304-316.

3. Blaschko H, Comline RS, Schneider FH, Silver M and Smith AD (1967) Secretion of a chromaffin granule protein, chromogranin, from the adrenal gland after splanchnic stimulation. Nature 215, 58-59.

4. Borrelli F and Ernst E (2002) Cimicifuga racemosa: a systematic review of its clinical efficacy. Eur J Clin Pharmacol 58, 235-241.

5. Borrelli F, Izzo AA and Ernst E (2003) Pharmacological effects of Cimicifuga racemosa. Life Sci 73, 1215-1229.

6. Burdette JE, Liu J, Chen SN, Fabricant DS, Piersen CE, Barker EL, Pezzuto JM, Mesecar A, Van Breemen RB, Farnsworth NR and Bolton JL (2003) Black cohosh acts as a mixed competitive ligand and partial agonist of the serotonin receptor. J Agric Food Chem 51, 5661-5670.

7. Calogero AE, Gallucci WT, Chrousos GP and Gold PW (1988) Catecholamine effects upon rat hypothalamic corticotropinreleasing hormone secretion in vitro. J Clin Invest 82, 839846.

8. Chen SN, Fabricant DS, Lu ZZ, Zhang H, Fong HH and Farnsworth NR (2002) Cimiracemates A-D, phenylpropanoid esters from the rhizomes of Cimicifuga racemosa. Phytochemistry 61, 409-413.

9. Chen W, He R, Li Y, Li S, Tsoi B and Kurihara H (2011) Pharmacological studies on the anxiolytic effect of standardized Schisandra lignans extract on restraint-stressed mice. Phytomedicine 18, 1144-1147.

10. Chrousos GP and Gold PW (1992) The concepts of stress and stress system disorders. Overview of physical and behavioral homeostasis. JAMA 267, 1244-1252.

11. Chrousos GP and Kino T (2007) Glucocorticoid action networks and complex psychiatric and/or somatic disorders. Stress 10, 213-219.

12. Cicek SS, Khom S, Taferner B, Hering $S$ and Stuppner $H$ (2010) Bioactivity-guided isolation of $\mathrm{GABA}(\mathrm{A})$ receptor modulating constituents from the rhizomes of Actaea racemosa. J Nat Prod 73, 2024-2028.

13. Coplan JD, Gorman JM and Klein DF (1992) Serotonin related functions in panic-anxiety: a critical overview. Neuropsychopharmacology 6, 189-200.

14. Cunningham ET Jr and Sawchenko PE (1988) Anatomical specificity of noradrenergic inputs to the paraventricular and supraoptic nuclei of the rat hypothalamus. J Comp Neurol 274, 60-76.

15. Cunningham ET Jr, Bohn MC and Sawchenko PE (1990) Organization of adrenergic inputs to the paraventricular and supraoptic nuclei of the hypothalamus in the rat. J Comp Neurol 292, 651-667.

16. De Vry J (1995) 5-HT1A receptor agonists: recent developments and controversial issues. Psychopharmacology 121, 126.

17. Dunn AJ and Berridge CW (1990) Physiological and behavioral responses to corticotropin-releasing factor administration: is CRF a mediator of anxiety or stress responses? Brain Res 15, 71-100.

18. Einbond LS, Soffritti M, Esposti DD, Park T, Cruz E, Su T, Wu HA, Wang X, Zhang YJ, Ham J, Goldberg IJ, Kronenberg F and Vladimirova A (2009) Actein activates stress- and statin-associated responses and is bioavailable in SpragueDawley rats. Fundam Clin Pharmacol 23, 311-321.

19. Fabricant DS, Nikolic D, Lankin DC, Chen SN, Jaki BU, Krunic A, van Breemen RB, Fong HH, Farnsworth NR and Pauli GF (2005) Cimipronidine, a cyclic guanidine alkaloid from Cimicifuga racemosa. J Nat Prod 68, 1266-1270.

20. Goi N, Hirai Y, Harada H, Ikari A, Ono T, Kinae N, Hiramatsu M, Nakamura K and Takagi K (2007) Comparison of peroxidase response to mental arithmetic stress in saliva of smokers and non-smokers. J Toxicol Sci 32, 121-127.

21. Jedema HP and Grace AA (2004) Corticotropin-releasing hormone directly activates noradrenergic neurons of the locus ceruleus recorded in vitro. $J$ Neurosci 24, 9703-9713.

22. Kanamaru Y, Kikukawa A and Shimamura K (2006) Salivary chromogranin-A as a marker of psychological stress during a cognitive test battery in humans. Stress 9, 127-131.

23. Kanno T, Asada N, Yanase H, Iwanaga T, Ozaki T, Nishikawa Y, Iguchi K, Mochizuki T, Hoshino $\mathrm{M}$ and Yanaihara $\mathrm{N}$ (1999) Salivary secretion of highly concentrated chromogranin A in response to noradrenaline and acetylcholine in isolated and perfused rat submandibular glands. Exp Physiol 84, 1073-1083.

24. Kent JM, Mathew SJ and Gorman JM (2002) Molecular targets in the treatment of anxiety. Biol Psychiatry 52, 10081030.

25. Khan S, Michaud D, Moody TW, Anisman H and Merali Z (1999) Effects of acute restraint stress on endogenous adrenomedullin levels. Neuroreport 10, 2829-2833.

26. Kirschbaum C and Hellhammer DH (1994) Salivary cortisol in psychoneuroendocrine research: recent developments and applications. Psychoneuroendocrinology 19, 313-333.

27. Kuraishi S, Kato M and Tsujioka B (1957) Development of the Uchida-Kraepelin psychodiagnostic test in Japan. Psychologia 1, 104-109.

28. Lai GF, Wang YF, Fan LM, Cao JX and Luo SD (2005) Triterpenoid glycoside from Cimicifuga racemosa. J Asian Nat Prod Res 7, 695-699.

29. Li GY, Ueki H, Kawashima T, Sugataka K, Muraoka T and Yamada S (2004) Involvement of the noradrenergic system in performance on a continuous task requiring effortful attention. Neuropsychobiology 50, 336-340.

30. Martin GN (1998) Human electroencephalographic (EEG) response to olfactory stimulation: Two experiments using the aroma of food. Int J Psychophysiol 30, 287-302.

31. Nadaoka I, Watanabe K, Yasue M, Sami M, Kitagawa Y and Mimaki Y (2012) Oral administration of Cimicifuga racemo$s a$ extract attenuates immobilization stress-induced reactions. 
Nat Prod Commun 7, 15-18.

32. Nadaoka I, Yasue M, Sami M and Kitagawa Y (2012) Oral administration of Cimicifuga racemosa extract affects immobilization stress-induced changes in murine cerebral monoamine metabolism. Biomed Res 33, 133-137.

33. Nakane H, Asami O, Yamada Y, Harada T, Matsui N, Kanno $\mathrm{T}$ and Yanaihara N (1998) Salivary chromogranin A as an index of psychologic stress response. Biomed Res 19, 401-406.

34. Nakane H, Asami O, Yamada Y and Ohira H (2002) Effect of negative air ions on computer operation, anxiety and salivary chromogranin A-like immunoreactivity. Int $J$ Psychophysiol 46, 85-89.

35. Nakazato K and Mizoguchi T (1982) Development and validation of Japanese version of State-Trait Anxiety Inventory. Shinshin-Igaku 22, 107-112.

36. Ng V, Koh D, Mok BY, Chia SE and Lim LP (2003) Salivary biomarkers associated with academic assessment stress among dental undergraduates. J Dent Educ 67, 1091-1094.

37. Noto Y, Sato T, Kudo M, Kurata K and Hirota K (2005) The relationship between salivary biomarkers and state-trait anxiety inventory score under mental arithmetic stress: a pilot study. Anesth Analg 101, 1873-1876.

38. Obara S and Iwama H (2005) Assessment of psychological tension after premedication by measurement of salivary chromogranin A. J Clin Anesth 17, 554-557.

39. Powell SL, Godecke T, Nikolic D, Chen SN, Ahn S, Dietz B, Farnsworth NR, van Breemen RB, Lankin DC, Pauli GF and Bolton JL (2008) In vitro serotonergic activity of black cohosh and identification of $\mathrm{N}$ (omega)-methylserotonin as a potential active constituent. J Agric Food Chem 56, 1171811726.

40. Ray WJ and Cole HW (1985) EEG alpha activity reflects attentional demands, and beta activity reflects emotional and cognitive processes. Science 228, 750-752.

41. Reame NE, Lukacs JL, Padmanabhan V, Eyvazzadeh AD, Smith YR and Zubieta JK (2008) Black cohosh has central opioid activity in postmenopausal women: evidence from naloxone blockade and positron emission tomography neuroimaging. Menopause 15, 832-840.

42. Rhyu MR, Lu J, Webster DE, Fabricant DS, Farnsworth NR and Wang ZJ (2006) Black cohosh (Actaea racemosa, Cimicifuga racemosa) behaves as a mixed competitive ligand and partial agonist at the human mu opiate receptor. J Agric Food Chem 54, 9852-9857.

43. Rohleder N and Nater UM (2009) Determinants of salivary alpha-amylase in humans and methodological considerations. Psychoneuroendocrinology 34, 469-485.

44. Rowland NE and Dunn AJ (1995) Effect of dexfenfluramine on metabolic and neurochemical measures in restraintstressed ob/ob mice. Physiol Behav 58, 749-754.

45. Sanchez O, Arnau A, Pareja M, Poch E, Ramirez I and Soley
M (2002) Acute stress-induced tissue injury in mice: differences between emotional and social stress. Cell Stress Chaperones 7, 36-46.

46. Saper CB and Loewy AD (1980) Efferent connections of the parabrachial nucleus in the rat. Brain Res 197, 291-317.

47. Saper CB, Loewy AD, Swanson LW and Cowan WM (1976) Direct hypothalamo-autonomic connections. Brain Res 117, 305-312.

48. Saruta J, Tsukinoki K, Sasaguri K, Ishii H, Yasuda M, Osamura YR, Watanabe Y and Sato S (2005) Expression and localization of chromogranin A gene and protein in human submandibular gland. Cells Tissues Organs 180, 237-244.

49. Shimbo M, Kuroiwa C and Yokogoshi H (2004) The effects of carbohydrate consumption on stress levels in humans. $J$ Nutr Sci Vitaminol (Tokyo) 50, 283-285.

50. Speilberger CD, Gorusch RL and Lushene RD (1970) STAI Manual for the State-Trait Anxiety Inventory. Consulting Psychologists Press, Palo Alto, CA.

51. Steptoe A (1991) The links between stress and illness. J Psychosom Res 35, 633-644.

52. Struck D, Tegtmeier M and Harnischfeger G (1997) Flavones in extracts of Cimicifuga racemosa. Planta Med 63, 289.

53. Sugimoto K, Kanai A and Shoji N (2009) The effectiveness of the Uchida-Kraepelin test for psychological stress: an analysis of plasma and salivary stress substances. Biopsychosoc Med 3, 5 .

54. Tanaka M, Yoshida M, Emoto H and Ishii H (2000) Noradrenaline systems in the hypothalamus, amygdala and locus coeruleus are involved in the provocation of anxiety: basic studies. Eur J Pharmacol 405, 397-406.

55. Taupenot L, Harper KL and O'Connor DT (2003) The chromogranin-secretogranin family. $N$ Engl $J$ Med 348, 11341149 .

56. Watanabe K, Mimaki Y, Sakagami H and Sashida Y (2002) Cycloartane glycosides from the rhizomes of Cimicifuga racemosa and their cytotoxic activities. Chem Pharm Bull (Tokyo) 50, 121-125.

57. Winkler H and Fischer-Colbrie R (1992) The chromogranins A and B: the first 25 years and future perspectives. Neuroscience 49, 497-528.

58. Yamaguchi M, Kanemori T, Kanemaru M, Takai N, Mizuno $\mathrm{Y}$ and Yoshida H (2004) Performance evaluation of salivary amylase activity monitor. Biosens Bioelectron 20, 491-497.

59. Yanaihara H, Hata M, Nishikawa Y, Hoshino M, Yanaihara $\mathrm{N}$ and Murai M (1999) Application of region-specific immunoassay for human chromogranin A: substantial clue for detection and measurement of chromogranin $\mathrm{A}$ in human plasma. Regul Pept 80, 83-90.

60. Zhang JF and Zheng F (1997) The role of paraventricular nucleus of hypothalamus in stress-ulcer formation in rats. Brain Res 761, 203-209. 